\title{
LOS ANIMALES Y LOS MUNDOS POSIBLES
}

\author{
José Luis González Quirós \\ Universidad Rey Juan Carlos. Madrid
}

Resumen: El texto sugiere que tratar de comprender mejor la conducta animal supone hacerse cargo de que los animales no son diferentes de los seres humanos precisamente porque carezcan de conciencia o de inteligencia, y que hacerse cargo de esa tarea podría suponer mejoras de interés en nuestra imagen del mundo natural, porque podrían servir para acceder a otras dimensiones de la realidad que la conciencia animal sabe poner de manifiesto.

Palabras clave: Conciencia, Filosofía de la mente, Sujeto, Inteligencia, Razón, Instinto.

\section{Animals and Possible Worlds}

Abstract: The paper suggests that a better understanding of animal behavior implies overcoming the idea that animals are different from humans precisely in that they lack awareness or intelligence. The search for this understanding could lead us to notable improvements in our image of the natural world, which could allow us to access other dimensions of reality that animal consciousness knows how to reveal.

Keywords: Consciousness, Philosophy of Mind, Subject, Intelligence, Reason, Instinct.

Recibido: 22/10/2017 Aprobado: 5/11/2017

Animal life is much more orderly,

and ordered in a way much closer to human patterns, than tradition suggest.

Mary Migdley $(1995,49)$. 
Un mundo es, esencialmente, un cierto orden o sistema centrado en un sujeto, es otra cara de una conciencia que, sin embargo, no se agota en ella. Naturalmente, nuestra inteligencia nos invita a suponer un mundo que no necesite ser visto por nadie, porque no hay nada en ningún mundo que indique que esté siendo objeto de un sujeto, lo que nos conduce a pensar en un en sí que no necesite ser contemplado, pero acaso esa suposición constituya una ilusión, y es, en todo caso, un límite a nuestra capacidad de pensar, porque es obvio que hay una cierta contradicción en pensar o imaginar un mundo que nadie ve ni imagina.

Nuestra inteligencia es una máquina de sustancializar, del mismo modo que es maestra en ocultar la conciencia que le da vida y poder, de modo que la idea racionalista de sustancia ("id quod per se est et per se concipitur" ${ }^{1}$ ) es una especie de paradigma del trabajo conceptual de nuestra mente, crear un mundo en el que estamos extrañamente ausentes, al menos hasta que descubrimos la honda medida en que esa ausencia es el precio que se paga por nuestra identificación con la totalidad de lo que se muestra, de lo que hay.

Un mundo posible es un mundo que puede existir, que tal vez exista de hecho, sin que nadie sepa bien de él, porque no hay que confundir la idea de que un mundo sea esencialmente un algo contemplado con la de que nada en él pueda permanecer oculto, es decir, que la realidad desborda claramente la capacidad de control y de comprensión de cualquier conciencia determinada, aunque no pueda ser pensada sin ella. En este marco de ideas, al referirme a

1 Es la definición de Spinoza en su Ethica more geometrico demonstrata, parte I, 3 a definición. 
los animales y los mundos posibles apunto, esencialmente, a la hipótesis de que, aunque no podamos penetrar en la conciencia de los animales, aunque no podamos asistir en directo y primera persona a la manera en que un halcón localiza a su presa o a la forma en que una tortuga encuentra su camino de vuelta en la mar océana, tal vez sí podamos descubrir algunos de los hechos de ese mundo que permiten a los animales hacer las cosas que hacen y con la precisión con que pueden hacerlas y que, para lograrlo, es fácil que no sea la mejor de las estrategias la suposición, muy generalmente asumida, de que los animales carecen de conciencia o tienen una forma muy defectuosa de ella, en lugar de suponer que sean seres plenamente conscientes, si bien disfrutan de una forma de conciencia que los sitúa en un mundo muy distinto al nuestro, una conciencia que deberíamos considerar antes como distinta que como inferior, entre otras cosas, porque hay formas de comportamiento animal, en las que es muy difícil dejar de considerar que estén implicadas formas muy sofisticadas de conciencia, que parecen superar bastante ampliamente nuestras capacidades sensoriales y cognitivas. Y, de alguna forma, debiéramos admitir que, en la precisa medida en que podemos considerar conscientes a los animales, debiéramos atender a que ese carácter, que en el caso humano es férreamente único e individual (no hay acceso concebible a otra conciencia en cuanto tal), también lo sea en el caso animal, aunque existen formas de comportamiento que apuntan a algo que podríamos considerar una especie de conciencia compartida o colectiva, lo que nos obligaría a reconocer que puedan existir en la conducta animal formas de conciencia y de comportamiento que no sean completamente reducibles a determinaciones biológicas, que quepa imaginar en ellos ciertas maneras de libertad. 
No hay otra alternativa que el asombro cuando nos asomamos a las formas del comportamiento animal, esto nadie lo discute, pero hemos almacenado indebidamente la supuesta explicación de todas esas maravillas en la noción de instinto, una percha verbal ${ }^{2}$, apenas más, en la que colgamos nuestras ignorancias sobre ese mundo posible, ignoto para nosotros, efectivo y accesible para la conciencia específica de cada animal. Parte de las líneas que siguen se empeñan en armonizar modos de pensar no materialistas, ideas que suponen la especificidad irreductible de las conciencias, en el caso de los animales, e invitan a pensar que el modo de estar en el mundo que es específicamente suyo podría ser investigado, pero que para ello se necesitaría algo más que pericia biológica y destreza en el análisis comportamental, que sería necesario, en efecto, poner en juego ciertas formas hipotéticas de imaginación que traten de ponerse en el lugar del sujeto. No estará de más, por cierto, advertir que eso es lo que muchas veces se hace de manera inconfesada, cuando se suponen, acertada, pero reprimidamente, formas de actuación finalista o intencional en los animales cuya conducta se trata de comprender, lo que pone de manifiesto esa peculiar ambigüedad que solemos mantener en nuestros intentos de comprensión de la vida de los animales que más nos interesan. Lo que, en todo caso, sí podríamos proponernos es tratar de comprender los diferentes mundos en que viven las distintas especies animales, distinguiendo su cara puramente física de la interpretación subjetiva que lleva

2 Como dice Rodríguez Valls (2017, 134), "Posiblemente el término instinto sea un cajón de sastre para toda conducta de la naturaleza animal biológicamente determinada: no lo es menos que el término eficacia biológica”. 
Los animales y los mundos posibles

a cabo el sujeto animal, y, si acertamos a hacerlo, y en alguna medida ya lo hemos hecho, esos mundos pasarían a ser parte del nuestro, entrarían a formar parte de la realidad conocida, dejando de ser mundos que solo podemos imaginar.

\section{El interés filosófico del caso}

Una misión de la Filosofía, frecuentemente dominada por el cientifismo y el historicismo, dos tendencias que debieran evitarse porque suponen una ruina de la objetividad, es la de recordar la existencia de problemas sin resolver, una derivada de su función básica que es la de buscar la verdad, la de no resignarse a comulgar con ruedas de molino. El cientifismo vincula cualquier forma de objetividad con el azar, y el historicismo la arruina evocando continuamente su fragilidad. Es cierto que cualquier teoría de la verdad dista de ser enteramente satisfactoria, pero sean cuales sean las deficiencias que afectan a una intelección no problemática de tal cuestión, no podemos conformarnos con renunciar a la búsqueda de lo verdadero, de lo que aún no comprendemos, por muy conscientes que se nos quiera hacer de los límites que afectan a nuestra capacidad intelectual de esclarecer la naturaleza de las cosas, del tiempo, de la realidad.

Puede ser peligroso conformarse con la idea rortyana de que la verdad no es objeto de ninguna teoría filosóficamente interesante, a saber, el riesgo efectivo de estar legitimando la confusión entre conocimiento e ignorancia, exagerando el poder y las virtudes de la mera información al olvidar deliberadamente que la información es el envoltorio común al saber y al no saber, y 
que tener en cuenta quien es el sujeto que la lee y no cesar de remitirla a aquello de lo que nos habla, es, al menos, tan decisivo como poder manejarla. Un saber que no se vigila y que se conforma con su función social y pragmática puede convalidar cualquier forma de ignorancia por el camino más corto. Si la filosofía ha consistido siempre en una cierta resistencia a la tiranía de lo obvio, es evidente que ha de vérselas con esa clase de Ersatzs de lo verdadero, con el reino de ideas que se imponen y se usan, pero no nos dan ninguna pista nueva para avanzar, ni ayudan a distinguir el trigo de la verdad de la paja del mero parloteo. A través de esa lucha un poco quimérica con los límites de lo que sabemos es como se pueda abrir paso el filósofo, aunque persiga estrellas que se mueven lentamente, por decirlo con Santayana.

Me parece oportuno hacer este breve recuerdo de la naturaleza de nuestro oficio al abordar una cuestión que todavía no suele ser demasiado común en la literatura filosófica, que no lo ha sido, sobre todo, al indagar sobre la conciencia de los animales, por decirlo de la manera más rotunda posible, por el ánima que paradójicamente se les niega. Es una cuestión no sólo extraña, sino difícil, porque siempre lo es cualquier teorización sobre la conciencia, y no será fácil inmiscuirse en terrenos supuestamente bien acotados por una ciencia sin demasiados misterios aparentes como es la Zoología.

\section{El animal y el hombre como medida de todas las cosas}

Pese a que se repita con insistencia la idea de que muchos de los esfuerzos de la filosofía se han empleado en subrayar la singularidad humana, en declarar que el hombre es algo así como el centro del universo y la medida de 
todas las cosas, no cabe olvidar que ese programa de base ha sido sometido a muy diversas formas de cuestionamiento. Cierta forma de modernidad ha parecido cifrarse en una especie de degradación del ser del hombre en una jerarquía ontológica, tan imaginaria como imprecisa, por cierto. Imaginaria, digo, porque no puede sino considerarse excesiva la pretensión de catalogar que está implícita en toda jerarquización, e imprecisa porque nunca ha quedado claramente establecida la nomología de esa supuesta a ordenación, y en qué consistiría exactamente la rebaja. Es común reconocer que la obra de Darwin supuso un ataque bastante demoledor contra las concepciones antropológicas excesivamente basadas en la idea de la singularidad, y lo hizo porque puso el acento en la comunidad biológica existente entre lo humano y el resto del reino de los seres vivos. De una u otra manera, esa obra ha traído consigo una reforma de fondo en el panorama en el que se contempla la singularidad, de forma que sean los que fueren los méritos que se conceda a la peligrosa idea de Darwin, por emplear la expresión de Dennett, resulta obligado revisar el terreno genéricamente fronterizo en el que, por fuerza, han de residir los motivos que se invoquen a la hora de recolocar lo que se considere característico y específico de la naturaleza humana en un panorama ontológico más amplio que el meramente antropológico.

Los animales no humanos, por genérica que resulta la denominación que se podría aplicar a todo semoviente, desde los infusorios hasta seres realmente muy semejantes a nosotros mismos, y con una obvia relación de parentesco, ocupan un lugar destacado en esa descripción topográfica. Uno de los rasgos que se han impuesto en la modernidad consiste, precisamente, en el olvido de la condición anímica de los animales, en breve, en su caracte- 
rización como máquinas. No tengo autoridad suficiente para entrar en el detalle fino de la manera en que se ha producido este cambio tan peculiar, pero creo que no es fácil encontrar en la historia del pensamiento equívocos que hayan producido consecuencias tan generales, y tan negativas. A este respecto, volver a considerar las cosas de una manera, digamos, más aristotélica, debe tenerse, sin duda, por un progreso. Además, como no podía ser de otro modo, esa metafísica mecanicista del reino animal ha tropezado repetidamente con un hábito humano contrario, proclive a tratar a los animales, en especial a los que nos resultan más cercanos, desde luego a los domésticos, más en tanto que "personas" que en tanto que cosas o máquinas, aunque hayamos de emplear las comillas al recurrir a un término tan cargado como el de persona. Un suceso que podemos considerar paradigmático de esa contradicción en los hábitos es el famoso "asesinato metafísico", como lo llamó Etienne Gilson al recordar el episodio del gato de Malebranche, un filósofo que era por lo que se refiere a los animales, un mecanicista cartesiano en el plano metafísico, pero, al tiempo, un piadoso sacerdote particularmente cariñoso con su gato.

En el análisis que sigue, me propongo examinar las consecuencias que habría que sacar de ese cambio de perspectiva, y las ventajas teóricas que ello pudiera aportarnos. No lo hago, y quisiera dejarlo claro desde el principio, con la intención de servir de apoyo a propuestas como las que se conocen como "derechos de los animales" o similares, sin que eso signifique que no las considere interesantes, porque, en primer lugar, me parece que esa clase de asuntos ha de solventarse en terrenos más sentimentales y éticos que propiamente metafísicos, pero, en segundo lugar, porque considero que lo que 
Los animales y los mundos posibles

siempre he tenido por problema filosófico de primer orden, a saber, la relación entre el cuerpo y la conciencia, no se funda únicamente en las peculiaridades del caso humano, sino que es mucho más general, y afecta también a nuestra comprensión de los animales. Los animales, como los humanos, tienen un alma, y por eso se les llamó así, y la relación de esa su alma con su cuerpo es tan intrigante y tan difícil de comprender como sucede en el caso humano. Supongo que el que uno de los escritos más influyentes de la filosofía contemporánea de la mente haya sido, precisamente, ¿el famoso "What is like to be a bat?" de Nagel, debería servir como refrendo de lo que sugeriré. Es evidente, en cualquier caso, que en la medida que se abandone definitivamente la idea de que los animales carecen de alma, cosa que pudiera estar sucediendo más deprisa en la práctica que en la teoría, ese cambio de consideración podría tener consecuencias de todo tipo.

\section{Los animales degradados, un breve panorama}

La ausencia de interés hacia el mundo animal fue muy característica del pensamiento medieval, pues era una consecuencia de su falta de atención hacia lo que llamamos el mundo físico en su conjunto, un clima intelectual en el que se veía el ámbito natural como un mero escenario en el que se desarrollaba lo verdaderamente interesante, el drama temporal de la existencia humana, la historia del diálogo y la relación entre Dios y los humanos. En ese panorama, los animales eran mera decoración ${ }^{3}$ y su mayor utilidad con-

3 Sigo una observación de Sherrington al respecto (1984:185) 
ceptual consistía en su función metafórica, el león era una imagen del diablo, como la serpiente había sido la de la tentación. Es llamativo que lo que se puede considerar un resto de medievalismo (la caracterización de los animales como máquinas) se haya podido convertir en esa desanimación del reino animal que ha servido de apoyo a filosofías materialistas olvidando dos circunstancias: que Descartes mismo consideró al cuerpo humano como una máquina y que, para Descartes, lo único que una máquina no puede hacer es pensar, es decir, tener su propio mundo y ser, de alguna manera, distinto de él, tener conciencia.

Un segundo factor que ha contribuido poderosamente a esa relegación metafísica de los animales ha tenido que ver con la exaltación de la condición humana, que es específicamente moderna y/o romántica, es decir con alejar al hombre del reino natural para considerarlo, sobre todo, como un creador de mundos, como alguien que, de alguna manera, por mor de su libertad, mediante la historia o gracias a la cultura y la tecnología, se dota de una autoimagen que lo separa de lo meramente natural, y se da un ser específico en el que la animalidad no deja de ser sino una especie de obstáculo.

Si por el primer sendero se relega a los animales al universo de lo meramente material, a ser tokens de un mundo absolutamente determinista y limitado, mediante el segundo procedimiento, se priva a los animales de cualquier capacidad cognitiva, se considera que, a diferencia del hombre, capaz de crear su mundo, han de ser vistos como sujetos de conducta rígidamente establecida, seres instintivos, cuya única capacidad relevante consiste en ser y funcionar como sistemas adaptativos incapaces de hacer otra cosa que acomodarse al medio, de hacer algo distinto a reaccionar ante él. Medio 
Los animales y los mundos posibles

y mundo se convirtieron así en la filosofía biológica al uso, en sinónimos de animalidad y humanidad, de instintividad frente a inteligencia, de adaptación frente a libertad, de naturaleza frente a cultura.

\section{La inconsciencia animal}

Cuando se niega la conciencia a los animales suele hacerse sobre dos presunciones teóricas que convendría discutir: la primera de ellas es categorial, la segunda es de grado. En primer lugar, se supone que, puesto que los animales no son capaces de conducta racional, no saben hablar, por decirlo en breve, carecen de conciencia en absoluto, puesto que conciencia y conciencia humana se consideran una y la misma cosa: para quienes parten de este supuesto no hay conciencia sin racionalidad, y niegan, de pasada, algo que parece excesivo, que los animales tengan racionalidad procesual, que puedan actuar intencionalmente y modular su actuación en función de la manera en que perciben y valoran las situaciones que les afectan.

La segunda presunción reside en la idea de que los animales tienen, en todo caso, un tipo de conciencia menor, puesto que, según este parecer, están recluidos en un mundo en el que son particularmente eficaces, pero al precio de no comprender en absoluto su misma presencia en ese mundo ni plantearse la naturaleza del mismo, un contraste que se expresa en una de las dimensiones esenciales de la idea de instinto. Bergson $(1963,623)$ expresó con enorme rotundidad esta dualidad supuestamente irreductible entre inteligencia e instinto al afirmar que "Il y a des choses que lintelligence seule este capable de chercher, mais 
que par elle-même, elle ni trouverait jamais. Ces choses, linstinct seul les trouverait; mais il ne les cherchera jamais."

Este énfasis en la presunta incapacidad de buscar del instinto animal es un trasunto, sensu contrario, de la dramatización de las funciones de la mente humana, de la constatación de que nuestra conciencia es la causa y el artífice de la creación de una imagen especular de la realidad, que se debe, en último término, a la carencia que exhiben las cosas mismas al no mostrar un significado o un sentido definido, a la ausencia de una respuesta obvia a la pregunta por el sentido de cuanto existe, a lo que podemos llamar el cuestionamiento de la realidad del ego, un proceso intelectual en el que, como dice Gómez Pin (2005, 128) puede haber una sobreabundancia de pensamiento sin mayor relevancia de la conciencia misma. Es, sin duda, una capacidad metafísica de la conciencia humana que, desde luego, no parece encontrarse en los animales. Es la preocupación por la verdad, que nos puede apartar en muchas ocasiones de la preocupación por la subsistencia y que, como puede argüirse con razón (Rodríguez Valls 2017, 82), carece en muchas ocasiones, si bien no siempre, de cualquier utilidad, lo que acaba ocurriendo siempre que nos lleva a hacernos preguntas que no estamos en condiciones de responder.

Examinemos brevemente ambas presunciones. Habrá que empezar recordando un par de obviedades que frecuentemente se dejan de advertir. En primer lugar, no conocemos ninguna forma de conciencia que no sea la propia, lo que hace que cualquier afirmación sobre la conciencia, su naturaleza y sus formas se haya de hacer sobre una base que no es suficientemente común ni constatable y que, por ello, está expuesta a cierto tipo de objeciones de principio que, por razonables que puedan parecer, y sutiles que sean las argumentaciones en su 
favor, podrían no ser enteramente certeras, además de ser francamente insuficientes como para negar esa peculiar y muy básica forma de realidad. Se puede ser solipsista, pero no es obligado serlo por el hecho de que jamás tengamos acceso directo a otra conciencia que la nuestra ${ }^{4}$. En segundo lugar, y, en consecuencia, hemos de inferir la realidad de las conciencias ajenas del comportamiento del sujeto consciente, de su pertenencia a un orden biológico y cultural determinado, de su lenguaje y de las relaciones que con él mantengamos.

En el caso de la conciencia animal, hemos de partir, por tanto, de que, aunque las conductas que hemos de observar resultan ser extraordinariamente distintas en el caso de especies diversas, pero también suficientemente variadas en los casos de cada individuo singular, esas conductas tan diversas son precisamente nuestra única fuente para afirmar que poseen alma, pues no podemos asomarnos a ella, no podemos ver el mundo que ven ni sentir las afecciones que experimentan.

No discutiré, porque me parece fuera de razón hacerlo, el hecho de que el tipo de conciencia que poseemos los humanos, ese acceso a una inteligibilidad que posee una universalidad esencial, capaz de crear lenguajes abstractos, no parece al alcance de los animales, de forma que esa rara cualidad configura un tipo de conciencia, cuando el sujeto no está afectado por enfermedad o privación, seguramente diferente a la de cualquiera de los animales que conocemos. Reconociendo claramente esa distinción, acaso quepa sugerir que tal vez no estuviera de más considerar que nuestra inteligencia podría no ser el único tipo

4 Puede verse al respecto González Quirós (2011 b). 
posible de estructura abstracta, que, obviamente, posee limitaciones, como se echa de ver en las aporías que la afectan y que, algunos animales podrían tener ciertas formas de conciencia inteligente suficientemente distintas a las nuestras, pero no tanto como para obligarnos a pensar que en ellos obre siempre la naturaleza "por la disposición de sus órganos", sin conciencia inteligente alguna. De todas maneras, cuando se pretende ignorar una distinción tan relevante en un esquema excesivamente genérico ${ }^{5}$, a mi entender, se confunde la conciencia con un esquema comportamental y se ignora del todo la peculiaridad de la conciencia misma.

Ahora bien ¿cuál es la razón para negar conciencia a sujetos que no poseen una inteligencia racional? Eso sería equivalente a negar la conciencia a individuos enfermos, cuando sean incapaces de razonar, a las personas dormidas, y a los niños de corta edad, lo que no es razonable, en absoluto. A mi entender, el motivo de fondo por el que se suele llevar a cabo esta escisión tan fuerte entre conciencia inteligente (humana) e inconsciencia (animal) está fundado, muy especialmente, en consideraciones de carácter ético ${ }^{6}$, además de legitimarse con las de carácter lógico a las que se viene acudiendo, al menos, desde Aristóteles. Así, negarles la conciencia psicológica se ve reforzado por el hecho de que consideramos necesario negarles la conciencia moral al no poder aplicar al comportamiento de los animales la idea de libertad (que tantos niegan también a los humanos, como es sabido). Al no pretender hacerlos objeto de ninguna censura moral, hagan lo que hagan, razonando a la manera kantiana, entende-

5 Por ejemplo, Mosterin $(1999,72)$

6 Puede verse al respecto Gómez Pin (2005, 121 y ss.) 
mos que obran exclusivamente conforme a la naturaleza, mientras que la ética, que es menester también de la razón, nos asoma y nos coloca a los humanos en un reino de principios que está por encima de la naturaleza.

Esas dos negaciones, que de puro habituales parecen evidentes sin que esté claro que merezcan tanta confianza, se complementan para trazar el circulo en el que los animales aparecen demenciados, con la idea de que el conocimiento sensible puede ser explicado sin demasiados aspavientos de una forma puramente mecánica mediante un esquema funcional extremadamente sencillo que asemeja la sensación, y también el recuerdo, lo que es todavía más grave, y mucho menos defendible, a una mera reacción estimular, a un esquema simple y maquinal que puede ser pensado en ausencia completa de sujeto, es decir de conciencia.

Todas esas ideas, más o menos confusas, se vierten en el concepto de instinto, pero no deberíamos ocuparnos de él sin echar un vistazo al problema del conocimiento sensible, cuyo tratamiento ha resultado bastante determinante para prolongar la supuesta legitimidad teórica de la inconsciencia animal.

\section{La larga sombra de la filosofia moderna de la mente}

Lo que se conoce habitualmente como filosofía de la mente se ha desarrollado, sobre todo, en los ámbitos de la Filosofía anglosajona, y se ha centrado en un conjunto de problemas que de manera habitual se consideraban como malentendidos de épocas pretéritas. Los filósofos analíticos han tratado de superar las categorías tradicionales, y en especial el dualismo cartesiano, mediante una aproximación a lo que la ciencia puede indicarnos al respecto y, al tiempo, refi- 
nando mucho el lenguaje tratando de evitar la caída en lo que se consideran sus trampas. Esto ha favorecido un tratamiento genéricamente reductivo de ese universo de cuestiones, estrategia en la que ha jugado también un papel muy importante la aparición de una serie de novedades muy prometedoras ligadas a la teoría y la tecnología de los procesos de computación que estaban suponiendo una reconsideración bastante extendida de las nociones establecidas en torno a lo que significan nuestros conceptos intencionales: qué es pensar, tener conciencia, tener inteligencia y, en último término, cómo es hacerse cargo de la información relevante para el conocimiento de un entorno dado en el que desarrollar una conducta determinada. Las máquinas, pues, como ya lo hicieran en el siglo XVII, conforme al título del libro de Rossi, han vuelto a interrogar a los filósofos, a los biólogos y a los psicólogos sobre lo que con ellas se podría aprender sobre nosotros mismos.

Desde el punto de vista filosófico, el problema de la mente se convirtió en tal en el momento en el que los racionalistas, siguiendo a Descartes, modificaron de manera radical la noción de sustancia que se había recibido de la tradición. Es un tópico considerar que tal operación se llevó a cabo para poder recibir adecuadamente las nuevas formas de ver la naturaleza que estaba trayendo consigo la Física moderna. En todo caso, este género de preocupaciones pasó a formar parte de las cuestiones centrales del pensamiento del siglo XX, tanto en la forma bergsoniana como en la russelliana o en la de Wittgenstein. Se trata, ni más ni menos, que de saber hasta qué punto la ciencia física tiene capacidad de explicar el conjunto de la realidad o, por el contrario, qué es lo que queda fuera de sus alcances, de saber cómo obtienen significado nuestras proposiciones, de preguntarse si somos capaces de naturalizar del todo nuestras ideas 
sobre la mente sin dejar demasiadas huellas de violencia teórica tras de nuestros pasos.

A pesar de las muchas cautelas de los filósofos analíticos algunas de las cuestiones que interesan a la filosofía de la mente han sido frecuentemente objeto de una colonización por argumentos bastante fuera de lugar que, en ocasiones, han acabado por desahuciar el problema y ofrecer ese desalojo como verdadera solución. Pues bien, para abrirse paso en un tema como éste que, al decir de Kripke (1980, 155n), resulta espinoso, confuso y abierto, se hace necesario restablecer las vías de acceso a una cuestión real, pero sepultada por una auténtica catarata de filosofemas, para evitar que la pura razón, en su forma más descarnadamente verbal, termine por reducir a la nada aquello que no acaba de comprender.

Desde la condena moderna de las cualidades secundarias al limbo de la subjetividad, es decir al reino de la nada ontológica, casi nadie ha reparado en que lo que pensamos sobre lo que es ver o sobre cualquier otro sentido es de un primitivismo espantoso. En el fondo, la cuestión más difícil de que debería ocuparse una filosofía de la mente más abierta y menos prejuiciada es la de la conciencia misma y esto es especialmente cierto cuando nos las hemos de ver con lo que, desde los clásicos, se llama la conciencia sensible, a diferencia de la conciencia, digamos, abstracta o conceptual, de la inteligencia.

El olvido de la importancia de las cuestiones relativas al conocimiento sensible se ha podido apoyar en la presunción de que la comprensión de acciones tales como ver, oír y sentir no sea especialmente difícil, además en la estrategia de refugio en el lenguaje que está implícita en el llamado giro lingüistico, cuyos méritos no hay que desmerecer, pero que, en este campo, ha permitido la circu- 
lación como teóricamente valiosas de algunas explicaciones que, como mínimo, están notoriamente cojas.

Pondré un ejemplo muy patente de ello al referirme a un desarrollo relativamente reciente en la obra de Putnam. Es bien sabido que los partidarios de la llamada teoría de la identidad, y los funcionalistas, no saben qué hacer con los contenidos inmediatos de la conciencia, mientras que estiman cosa sencilla reducir lo que es la inteligencia. Incluso los propios "mentalistas" o "neodualistas" han aceptado el esquema postcartesiano, produciéndose una curiosa circunstancia para el que esté un poco familiarizado con la filosofía clásica, situación que como subrayó Jaegwon Kim $(1971,336)$, hace que mientras que para Platón, los pensamientos racionales eran las actividades paradigmáticas del alma, los hechos tan menudos como picores, dolores de muelas y punzadas están ahora entre los típicamente mencionados en la discusión filosófica como eventos mentales. Recientemente, Putnam ha tenido que reconocer que el programa reduccionista se apoyaba en una consideración deficiente de la filosofía, en la absurda suposición de que bastaba con partir de Descartes para suponer a renglón seguido que ya era hora de acabar con sus prejuicios y desterrar el dualismo. Así, como dice el filósofo americano (1997, 28), todo el mundo "sabía" (comillas de Putnam) que el problema mente-cuerpo tenía que ver con si las sensaciones eran o no materiales. El supuesto de tantos materialistas se fundaba en que, además de desconocer la filosofía clásica, habían oído hablar de que la materialización del conocimiento intelectual era cosa ya hecha por los tecnólogos de la informática profética. Tanto en la teoría de la mente como en la teoría del conocimiento sensible, la presunta relevancia de explicaciones formales y conductuales ha sido exagerada una y otra vez por quienes se han dejado seducir 
por la tentación de la simplicidad suponiendo que saben explicar lo que realmente no entienden, confundiendo una explicación capaz de proporcionar pistas para un conocimiento verdadero con cualquier estrategia verbal que dé, sin más, por explicado, lo que simplemente describe desde fuera, si se me permite usar, aunque sea brevemente, de la contraparte de la casi inevitable metámetáfora de la interioridad.

Si el conocimiento sensible es algo puramente material, los animales pueden tenerlo sin tener la mente consciente capaz de mayores hazañas, por más que también se pretenda explicarlas con analogías como la del aparato perceptor o la del procesamiento cerebral. Sin duda podemos hablar de aparatos perceptuales y de procesamiento de información, pero el mero hecho de hacerlo no explica todavía nada, queda en metáfora mientras no sepamos llegar por esa vía, o por otras muy distintas, a la explicación decisiva de fenómenos más finos, lo que supone, para empezar análisis más rigurosos y completos de aquello que se pretende reducir, si no se quiere que el paradigma de esta clase de conocimiento sea el lecho de Procusto. Confundir una posible vía de investigación con una explicación suficiente puede servir para alardear de grandes avances, pero no sirve realmente de nada. Lo que por estas vías sabemos de nuestra mente consciente es muy similar a lo que sabemos de la conducta animal cuando la explicamos en base a los instintos, muy poco realmente.

\section{La idea de instinto}

$\mathrm{El}$ término instinto no es precisamente moderno pues tiene una clara raíz latina; su uso habitual en Psicología y en Biología ha sufrido una serie de 
alteraciones porque, se diga lo que se diga, las modas también influyen en las terminologías científicas, en especial cuando se refieren a fenómenos que no se conocen de manera suficientemente completa.

En cualquier caso, el término instinto ${ }^{7}$ se reserva habitualmente para aquellas conductas animales, y también humanas, que no requieren conocimiento o conciencia para ser ejecutadas, de manera que eso excluye lo que proceda del aprendizaje y requiere un cierto carácter innato. La conducta instintiva se tiene de la misma manera que se tiene pico o alas, que se es carnívoro o herbívoro. Los conductistas tendieron a reducir el alcance explicativo de cualquier instinto en la medida en que destacaron intensamente que las conductas, humanas, pero también animales, eran fundamentalmente aprendidas. No mucho después, el innatismo volvió a ponerse en circulación a partir de la obra de Lorenz en los años cincuenta y al introducirse fórmulas que permitían distinguir el factor instintivo del aprendizaje, por ejemplo, con los famosos análisis de lo que se llamó impronta.

En términos del interés por la comprensión del modo de funcionamiento consciente de la mente humana, en los textos de antropología, el concepto de instinto continúa siendo un elemento de distinción fundamental entre humanos y animales. Por ejemplo, en el excelente libro de Rodríguez Valls $(217,117)$ se dice, a propósito de la idea de emoción, que "la conducta de los animales viene dada, generalizando, por el instinto". Creo que entre los filósofos esta es una idea que no exige demasiado discusión y, aunque Bergson

7 A propósito del término puede verse Bergson (1963, 319-331), Midgley (1995, 49 y ss) y Rodríguez Valls (2017, 115 y ss). 
no haya obtenido especial fortuna ni entre los analíticos ni entre los biólogos, se puede afirmar que su idea de instinto goza de un alto grado de vigencia, es decir que el instinto tiene una virtud eficaz, pero carece de capacidad de búsqueda, de intelección y, por tanto, de conciencia.

Trataré de razonar en el sentido contrario, partiendo de que muchos animales, decir que todos me parecería pretenciosamente excesivo, tienen una conducta específicamente intencional, lo que significa que ejercen un tipo de racionalidad procesual o finalista, es decir que atienden, en la medida de su capacidad, a las circunstancias del entorno, las evalúan y eligen una forma de actuar que les parece la más adecuada para resolver el problema que se les plantea. Cuando nosotros observamos una conducta animal bajo esta perspectiva notamos inmediatamente que el animal no vive exactamente en nuestro mundo, que ve cosas que no vemos y no ve otras que se les escapan y son obvias para nosotros, pero es difícil que ante formas de conducta altamente sofisticadas ${ }^{8}$, como la de la perdiz que simula cojera para atraer a una culebra que amenaza a sus polluelos, librándoles de su acoso, lo que implica arriesgar su vida si la treta le sale mal, o la de la manada de búfalos que reconsidera su huida frente a un grupo de jóvenes leones que ha apresado a uno

8 Ofrezco ejemplos tomados de los innumerables programas sobre conducta animal que aparecen en las televisiones y que son accesibles en Youtube. Soy muy consciente, por haber sido cocinero antes que fraile, de que tales programas pueden ser engañosos porque sus realizadores preparan las escenas para contar la historia que deseen, pero basta con observar la conducta de algunos animales domésticos para desechar una buena parte de los tópicos que imaginan una conducta animal guiada por el instinto y los reflejos y enteramente aparte de fines y controles autónomos. 
de sus miembros para dirigirse a su rescate venciendo el miedo y poniendo, finalmente, en fuga a los felinos, no sintamos una fuerte inclinación a desconsiderar explicaciones demasiado simplistas de la conducta de los animales y suposiciones que pretenden ignorar que su vida está regida por una forma de conciencia precisa del entorno y por un cálculo inteligente y adecuado a sus necesidades y posibilidades de lo que les conviene y lo que han de evitar.

Considerar que el instinto es razón suficiente para explicar toda una serie de conductas animales muy complejas es resolver de una forma excesivamente simple el caso. Admitir, por el contrario, que el animal se enfrenta con un mundo en el que debe aprender a valorar el significado de una serie de fenómenos y a desenvolverse entre ellos implica reconocer la existencia de una conciencia animal, de una inteligencia específica y de una cierta racionalidad intencional o procesual.

Está claro que también se puede pretender dar razón de esa clase de conductas con un esquema en el que la mente animal no juegue ningún papel, en el que una entidad como el instinto sirva para explicar las formas en que se articulan los estímulos y las respuestas. Parafraseando a Bergson, podríamos decir que es cierto que para un observador externo toda actividad puede ser reducida a un automatismo absoluto, pero con ello perderíamos una clave importante. Un mundo es un sistema de realidades que se relacionan de una determinada manera y lo interesante es que las cualidades extremadamente sorprendentes de muchas conductas animales nos advierten de que dentro de nuestro mundo hay otros que se nos escapan, aquellos, precisamente, que permiten a la conciencia animal obtener resultados que están enteramente fuera de nuestro alcance y comprensión. Cuando una mariposa puede locali- 
zar a su pareja a decenas de kilómetros a distancia, o cuando una bandada de decenas de patos puede volar en una formación perfectamente sincronizada, o cuando una tortuga o una anguila pueden volver a la costa de la que salieron a centenares de kilómetros del paraje marino en que se encuentran, es evidente que están desarrollando unas capacidades de adaptación al mundo, y de conducta en relación con él, que exigen unas formas de conocimiento muy específicas. Su conciencia, como la nuestra, solo podemos interpretarla como un sistema en el que datos objetivos del mundo se transforman en aptitudes, sensaciones y propósitos que cada individuo interpreta y ejecuta con sorprendente eficacia. Ese es el aspecto que Bergson subrayaba en su contraposición entre instinto e inteligencia, la capacidad de encontrar, pero esa capacidad de encontrar se basa, necesariamente, en una doble realidad, la existencia de ese algo que se halla y la capacidad consciente, al menos de alguna manera, de reconocerlo y seguirlo, porque, no se olvide, hay mariposas que no encuentran a sus parejas, tortugas que se pierden y patos que, al menos en algunos casos, tropiezan con sus adláteres. No hay, pues, necesidad alguna de suponer ninguna suerte de mecanismo inequívoco, de automatismo ciego en esas conductas tan extraordinarias para nuestra capacidad, es más económico suponer que la conciencia de los animales sabe ver y entender cosas que a nosotros se nos escapan, como, de otra manera, tampoco alcanza a vislumbrar otros rasgos de la realidad que nosotros manejamos con cierta facilidad.

La noción de instinto incorpora una serie de capacidades a las que habría que encontrar un equivalente menos mecanicista, en especial para explicar formas de conducta más sofisticadas que las muy elementales y fijas que, sin duda, existen. Cabe reconocer, como hace Migdley, que existan instintos 
abiertos, pero también podríamos admitir que muchas de las funciones que se atribuyen a una capacidad explicativa tan amplia puedan ser traducidas a pautas y formas de actuar en las que la conciencia animal pueda jugar un papel más determinante. Así, determinadas características, o pautas de conducta, de lo que se considera instintivo, tales como el supuesto automatismo de la respuesta, la inevitabilidad de la conducta, la universalidad entre los miembros de una determinada especie, su no modificabilidad, o el no necesi$\operatorname{tar}$ de aprendizaje, puedan ser debidamente matizados en un esquema explicativo que no rechace la posibilidad de intermediación consciente de un sujeto, animal en este caso.

\section{Conciencia e intencionalidad animal}

$\mathrm{Si}$, como supongo, es más fácil entender la extraordinaria conducta de los animales (también la ordinaria, por supuesto) suponiendo que tienen un tipo especial de conciencia, aunque también podría decirse que poseen una conciencia, sin más, dotada de fuentes sensoriales muy distintas, será también más razonable admitir que los animales son capaces de conductas inteligentes, de perseguir fines de manera intencional y, en cierto modo, deliberada. En la actualidad se ha hecho bastante más común admitir claramente el carácter inteligente de muy diversas conductas animales, tal vez al tiempo en el que se ha empezado a subrayar que ciertos aspectos de la racionalidad humana puede que no sean los más obvios para establecer esa diferencia que existe tanto interés en resaltar, al menos, desde la influencia del darwinismo. Como dice Mary Migdley (1995, 43) bien podríamos habernos fijado en 
otros aspectos muy singulares de la humanidad para establecer esa ansiada diferencia, tales como la tecnología, la crueldad para con otros humanos, o determinadas características de la conducta sexual. Sin embargo, ha sido corriente, al menos desde Aristóteles, subrayar el carácter intelectualmente excepcional del hombre, y esa fijación ha venido actuando como un elemento que ha sido capaz de distorsionar el reconocimiento de las capacidades específicamente cognitivas de los animales, reducirlos a meras repeticiones de un modelo, a privarles de cualquier clase de ingenio, como hizo Descartes en la quinta parte de su Discurso, cuando afirmó que, aun cuando puedan hacer cosas que nos maravillen o sorprendan, "es la naturaleza la que en ellos obra por la disposición de sus órganos, como vemos que un reloj, compuesto solo de ruedas y resortes, puede contar las horas y medir el tiempo más exactamente que nosotros con toda nuestra prudencia”.

Estar abiertos a considerar la conciencia de los animales como un elemento causalmente eficaz en su conducta, equivale a admitir que los individuos de numerosas especies, en especial de mamíferos, pero no únicamente ellos, tienen lo que podíamos llamar un carácter o una cierta personalidad. De la misma manera que el intento de aplicar una explicación finalista puede suponer que se pierda la oportunidad de entender cómo funciona efectivamente un mecanismo, deberíamos admitir que el intento de exorcizar toda suerte de finalidad nos veta la capacidad de entender realidades tan simples como la agudeza de un cuchillo hecho para cortar. Ese mismo tipo de prejuicio ha ocultado la evidencia del carácter claramente intencional de la conducta animal y el hecho de que en la relación entre los fines que persigue, por su naturaleza o por su determinación, y los medios que empleará para alcanzar- 
los existe cierta especie de racionalidad, una razón, diríamos, instrumental o mediática. Cuando el gato se oculta para tratar de cazar un pájaro está comportándose con plena lógica, y cuando el pájaro advierte la amenaza gatuna más le vale que emplee la lógica de la huida que le va a permitir seguir vivo.

Nuestra capacidad de comprender este tipo de situaciones funciona, evidentemente, por analogía con lo que hacemos y entendemos, y existe, sin duda, el riesgo de antropomorfizar indebidamente la conducta animal al asimilarla a la nuestra, aunque exista también el riesgo contrario: negar la conciencia sencillamente porque no es como la nuestra, pero por más que se traten de evitar las hipótesis innecesarias, no podemos negarnos a admitir la evidencia de que en la conducta animal, que se nutre de informaciones sobre el mundo mediante algunos sentidos bastante similares a los nuestros, pero también de otras, ha de existir un centro de proceso, y hay un lugar para introducir en él un sujeto, la realidad de un ser que es consciente y que se rige, muy como nosotros, precisamente pero por aquello que percibe y entiende. Luego podemos insistir cuanto se quiera en que a esa conciencia le faltan muy probablemente cualidades que solo nosotros poseemos, y podemos interpretar esa carencia como un claro indicio de superioridad intelectual humana. Nada que objetar, pero lo que me parece tener mayor interés es que en la medida en que pensemos así, acabaremos por reconocer que los animales pueden ayudarnos a conocer el mundo común en que ellos y nosotros vivimos, que el estudio de su conducta y de su constitución biológica, ya que no podemos asomarnos directamente a su conciencia, podría mostrarnos dimensiones y aspectos de la realidad del único mundo que compartimos, 
que hasta ese momento habrían permanecido enteramente fuera del alcance de nuestra capacidad.

En efecto, no tenemos ninguna evidencia de qué es lo que orienta a las aves en su vuelo, o de qué es lo que percibe el fino olfato de un sabueso, pero estamos perfectamente autorizados a pensar que se trata de algún rasgo de lo real que tal vez nunca seremos capaces de percibir pero que tendríamos que intentar comprender. Desde este punto de vista, el estudio de la conducta animal, de sus emociones y de sus formas de entender y organizar el mundo, debiera ser un objetivo realmente importante porque podría revelarnos aspectos del que realmente existe que podrían ampliar grandemente nuestra comprensión de la naturaleza, y que acaben siendo, incluso, de enorme utilidad. No creo, ya lo he advertido, que seamos nunca capaces de ver el mundo con los ojos de un halcón, pero sí estoy convencido que si aprendiéramos a entender la forma en que ve y vuela podríamos utilizar ese mundo de posibilidades en nuestro provecho, $y$, para poder hacerlo, parece bastante razonable apartarse de la imagen del animal como un mecanismo elementalmente gobernado por un autómata fisiológico.

En una ocasión anterior (González Quirós, 2011 a) me he referido a la sugerencia de un pensador tan escasamente mitómano como Freeman Dy$\operatorname{son}^{9}$ que ha sugerido la posibilidad, por ejemplo, de instrumentar alguna forma de radiotelepatía, una comunicación directa de sentimientos y pensamientos entre cerebro y cerebro. A mi entender, eso no es algo radicalmente distinto a lo que hacemos cuando hablamos por teléfono, por ejemplo. Para

9 http://www.edge.org/q2009/q09_3.html 
hacer posible la radiotelepatía, nos dice Dyson, sería necesario saber convertir señales neurales en señales de radio, y construir radiorreceptores microscópicos, además de saber reconocer algo así como el significado consciente de los procesos neurales, cosa que Dyson no menciona. Se trata de saberes que no poseemos, pero que no son enteramente inconcebibles. Dyson especula también con la posibilidad de sentir lo que un pájaro siente al volar, o lo que un ciervo siente al ser abatido, posibilidad que me parece algo más quimérica, incluso aunque esas formas de telecomunicación progresen sin descanso, pero no estamos aquí para poner puertas al campo.

Perseguir ese tipo de objetivos supone trabajar en la biología animal y en la física del mundo sensible y eso se hará con muchas menos dificultades si asumimos de manera sencilla que el animal vive en un mundo de sentidos del que, a su manera, es perfectamente consciente.

La filosofía puede hacer algo en este panorama, a saber, considerar que no debiéramos empeñarnos en la defensa de categorías que puedan ser sustituidas con ventaja, y en esa posible sustitución es esencial marcar con la mayor claridad las zonas de sombra y de positiva ignorancia que forman parte de las imágenes comunes de la realidad. Es obvio que muchas de las limitaciones de nuestro conocimiento residen en cuestiones como la que acabamos de manosear, en que tal vez no podamos saber cuánto desearíamos y seamos capaces de imaginar. Pero ser consciente de que no se sabe es algo más, y por cierto algo mejor, que el mero saber. En último término, la filosofía contribuye a dibujar con mayor inteligencia la frontera de lo que sabemos y lo que creemos saber, esa frontera entre la ciencia y la filosofía en la que se encuentran algunas de nuestras mejores esperanzas de lucidez: es ese espacio intelectual 
en el que, efectivamente, y como dijo Koyré, a propósito de las paradojas de Zenón, la discusión de los verdaderos problemas filosóficos no se cerrará jamás.

\section{Bibliografia empleada}

J. Arana, La conciencia inexplicada, Madrid, Biblioteca Nueva, 2015.

H. Bergson, Euvrres, París, Presses Universitaires de France, 1963.

D. J. Chalmers, "Facing up to the problem of consciousness", Journal of Consciousness Studies, 2 (3), 1995, pp. 200-219.

D. J. Chalmers, The Conscious Mind, In Search of a Fundamental Theory, New York, Oxford University Press, 1996.

E. Gilson, La unidad de la experiencia fillosófica, Madrid, Rialp, 1967.

J. L. González Quirós, "La teoría de la mente: de la inteligencia artificial a la inteligencia híbrida”, en Diosdado, Concepción, Rodríguez Valls, Francisco y Arana, Juan Eds., Neurofilosofia. Perspectivas contemporáneas, Sevilla y Madrid, Thémata y Plaza y Valdés, 2010, pp. 153176.

J. L. González Quirós, "El nudo del mundo. Metáforas y argumentos en relación con un problema intratable", en Diosdado, Concepción, Rodríguez Valls, Francisco y Arana, Juan Eds., Asalto a lo mental. Neurociencias, consciencia y libertad, Madrid, Siglo XXI EditoresBiblioteca Nueva, 2011, pp. 89-97.

J. L. González Quirós, “¿Podemos ir más allá de Aristóteles en relación con la idea de inteligencia?” en Francisco Rodríguez Valls, Ed. La inteligencia en la naturaleza. Del relojero ciego al ajuste fino del universo, Madrid, Biblioteca Nueva, 2012, pp. 51-60.

J. L. González Quirós, “¿Es necesaria una teoría de la conciencia?, Naturaleza y libertad, 7, pp. 357-374.

J. Kim, Jaegwon, "Materialism and the criteria of the mental", Synthese, 22, 1971.

S. Kripke, Naming and Necessity, Oxford, Blackwell, 1980.

M. Migdley, Beast and Man. The Roots of Human Nature, New York, Routledge, 1995.

J. Mosterin, ¡Vivan los animales!, Madrid, Debate, 1999. 
José Luis González Quirós

A. Prochiantz, "Instinto e inteligencia", Investigacion y ciencia, Inteligencia viva, $3^{\circ}$ trimestre, 1999, pp. 68-70.

H. Putnam, Hilary "Acerca de un mal uso del teorema de Gödel en la especulación sobre la mente", Revista de libros, no 3, III-1997, pp, 31-32.

H. Putnam, La trenza de tres cabos. La mente, el cuerpo y el mundo, Madrid, Siglo XXI de España Editores, 2001.

E. Schrödinger, What is Life \& Mind and Matter \& Autobiographical Sketches, Cambridge, Cambridge University Press, 1996.

C. S. Sherrington, Hombre versus naturaleza, Barcelona, Tusquets, 1984.

José Luis González Quirós

jlgonzalezquiros@gmail.com 